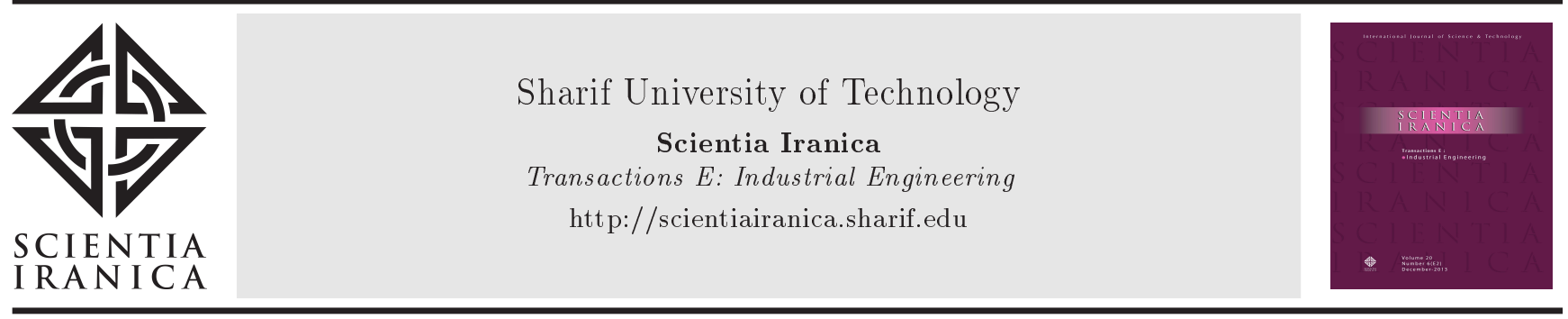

Research Note

\title{
An integrated fuzzy QFD-MCDM framework for personnel selection problem
}

\author{
E. Özgörmüş, A.A. Şenocak, and H.G. Gören* \\ Department of Industrial Engineering, Kinikli Campus, Pamukkale University, Kinikli, 20070, Denizli, Turkey.
}

Received 23 November 2018; received in revised form 26 September 2019; accepted 28 December 2019

\section{KEYWORDS \\ Multi criteria \\ decision-making; \\ Personnel selection; \\ Fuzzy QFD; \\ Fuzzy DEMATEL; \\ Fuzzy GRA.}

\begin{abstract}
In today's competitive and high technology world, companies are forced to differentiate themselves with continuous improvement. They need creative, well-educated, and self-confident human resources more than ever. Hiring the right person to the right job plays a significant role on firm growth. The goal of this paper is to propose a systematic approach to Personnel Selection Problem (PSP) of a textile company in Turkey by considering various performance requirements and criteria. The proposed framework consists of three phases. Initially, fuzzy Decision-Making Trial and Evaluation Laboratory (DEMATEL) method is used to weight social criteria. Then, weights of technical requirements are calculated by applying fuzzy Quality Function Deployment (QFD) method allowing the evaluation of the interrelationship and relevance of social and technical criteria. Finally, by considering the criteria scores obtained in the previous stage, fuzzy Grey Relationship Analysis (GRA) method is applied to rank the alternatives. The method has been illustrated by a case study and compared to the current approach used in the company. The results show that the proposed method can effectively deal with PSP and help the company establish a systematic and unbiased approach to the problem.
\end{abstract}

(C) 2021 Sharif University of Technology. All rights reserved.

\section{Introduction}

Recruitment is one of the primary functions of organizations. Selection of the most appropriate candidate among alternatives that performs the requirement of the job is defined as Personnel Selection Problem (PSP) [1]. This problem is very important because correcting the consequences of a wrong decision to hire someone is very difficult, costly, and timeconsuming [2]. As mentioned in [3], the main issues related to this problem are to determine the weight of the

*. Corresponding author. Tel.: +90 5057656676 E-mail address: hgoren@pau.edu.tr (H.G. Gören)

doi: $10.24200 /$ sci.2019.52320.2657 criteria that affect the problem, use linguistic and/or numerical scales to evaluate applicants, and integrate the evaluation results, and rank applicants. To answer all these questions, a systematic and analytical method is needed. Since people working in an organization affect its performance, numerous researches have been conducted in this field. Considering different criteria and alternatives, the PSP is a typical example of a Multi-Criteria Decision-Making problem (MCDM) and several different MCDM approaches and their hybrids have been proposed to solve this problem.

However, there is an important gap regarding to the employer ideal personnel and employee selected for the job. Nearly all studies focusing on this subject have considered different criteria and used these defined criteria to evaluate alternatives. No attention has 
been given on the comparison between the employer ideal personnel and the employee selected. It is important that the employee selected should match employer requirements and this issue should be taken into consideration in the selection process. From this point of view, we are aiming to bridge this gap by providing an integrated framework. The most significant contribution of this study to the PSP literature is providing a systematical and analytical integrated method, considering social and technical criteria and their interactions in the recruitment process, simultaneously. Generally, in the recruitment process, multiple decision-makers are usually preferred instead of a single decision-maker to avoid bias. As we all know, decisionmakers use qualitative and quantitative factors to evaluate candidates. For instance, the experience of a person can be defined with a crisp number however, for the evaluation of communication skills or creativity, linguistic variables are easier to use. In dealing with this kind of variable, the fuzzy set theory [4] has been accepted as a very useful decision framework that incorporates imprecise judgments inherent in the personnel selection process [5]. In the past decade, the number of papers addressing PSP in fuzzy environments has rapidly increased (see the comprehensive literature review provided by Afshari et al. [6]). There have been many applications of fuzzy Analytical Hierarchical Process (AHP) (see e.g. [7-11]) fuzzy Analytical Network Process (ANP) (see e.g. [3,12]), fuzzy TOPSIS (see e.g. [5,13-16]), and hybrid methods of those such as $[3,17,18]$ in literature. The other contribution of this study is to help organizations overcome bias in the recruitment process.

The proposed approach consists of three different approaches, fuzzy Decision-Making Trial and Evaluation Laboratory (DEMATEL)-fuzzy Quality Function Deployment (QFD) and fuzzy Grey Relational Analysis (GRA). Although there are many methods for the recruitment process, to the best of our knowledge none of them has dealt with evaluating these criteria and their interactions simultaneously. In addition, the determination of the Social Attributes (SA) required by job candidates and the weighting of these criteria can sometimes be very complicated and time-consuming. At this stage, the fuzzy DEMATEL method is very useful and applicable. In the proposed method, the fuzzy QFD method is used to establish the relationship between SA and Technical Requirements (TR). Finally, in the evaluation and ranking stage, the fuzzy GRA method has been applied due to the efficiency in group decision making problems [19].

The rest of the paper is structured as follows: Section 2 reviews the related literature focusing on PSP. The method currently used by the company is explained in the Section 3, and the suggested method is explained in the Section 4. The results of the case study are given in Section 5. Finally, the last section summarizes the findings and presents some future research directions.

\section{Literature review}

Considering the consequences of the wrong decision of recruitment, PSP has been extensively studied by many researchers and practitioners. The current articles in the literature related to personnel selection suggest integrated or hybrid methods since conventional MCDM methods cannot deal with the complexity of the PSP. Recently, many attempts have been made to combine or improve methods to find the most suitable personnel.

A contemporary study by Jasemi and Ahmadi [20] have proposed a novel fuzzy ELECTRE method to choose an industrial engineer for pipe manufacturing plant in Iran, and then the results have been compared to those of TOPSIS. Samanlioglu et al. [18] have utilized fuzzy TOPSIS and fuzzy AHP for the Information Technology (IT) personnel selection process of Turkish dairy company. Ji et al. [21] have proposed a fuzzy method based on Multi-Valued Neutrosophic Sets (MVNS) to select the sales supervisor for a manufacturing company. In order to select the personnel for assembly lines, Efe and Kurt [22] have integrated TOPSIS with interval type-2 trapezoidal fuzzy numbers and applied the method. Dahooie et al. [23] have selected the best IT personnel from five candidates by applying SWARA (Step-wise Weight Assessment Ratio Analysis) and grey ARAS (Additive Ratio Analysis). Deliktas and Ustun [24] have solved the assignment problem of students to the predetermined programs, namely Erasmus program, by using fuzzy MULTIMOORA and multichoice conic goal programming. Koutra et al. [25] have developed a multi criteria MCDM approach for personnel selection in the maritime industry, based on AHP and Correspondence Analysis (CA). Urosevic et al. [26] have proposed an approach based on the use of the SWARA and the WASPAS (the Weighted Aggregates Sum Product Assessment) methods and a numerical example is conducted to select the sales manager in the tourism sector. SWARA and ARAS methods are combined to select the sales manager by Karabasavic et al. [27]. Another integrated method consisting of GRA and IFWA (Intuitionistic Fuzzy Weighted Averaging) has been presented in Zhang and Liu [1] and an example is implemented to present the computational process of the proposed method. Alguliyev et al. [28] have proposed a hybrid algorithm including the worst-case method and fuzzy Vise Kriterijumska Optimizacija I Kompromisno Resenje (VIKOR). In the study, criteria weights have been calculated by the worst-case method and then by using fuzzy VIKOR candidates have been sorted. In addition, the results have been compared with those 
obtained by modified fuzzy VIKOR. Chang [29] has successfully applied a method of fuzzy Delphi, ANP, and TOPSIS to select the best candidate of public relations personnel.

Chien and Chen [30] have developed an effective personnel selection mechanism to find the talents who are the most suitable to their own organizations by using a data-mining framework based on decision tree and association rules to generate useful rules for personnel selection. Chen and Cheng [31] have developed computer based decision support system to rank the candidates based on the metric distance method.

The research conducted by Sang et al. [16], Canós et al. [32], Kabak [33], Baležentis et al. [34], and Lin [3] are other good examples of the applications of fuzzy methods in the PSP literature. The interested reader can refer to Afshari et al. [6] for further applications of fuzzy logic in PSP.

The literature review shows that different MCDM approaches and their hybrid methods have been utilized to solve PSP. The most widely used ones are TOPSIS and AHP. This can be due to their simplicity. In recent years, new approaches such as TODIM and SWARA have also been applied to this problem (see Table 1). However, except for Chang [29] and Dağdeviren [35], nearly all these studies have not considered the interactions among criteria. Neglecting these interactions might lead to a wrong decision, which might affect the organization. Thus, the interactions should be taken into consideration in order to hire the right person. From this point of view, in this paper, the interactions between criteria have been handled using fuzzy DEMATEL and QFD, which have not been utilized to solve the problem in the previous literature. Table 1 briefly summarizes the studies on PSP under the headings of method and application area.

Before explaining the proposed method, the next section explains the current approach used by the company in the case study.

\section{The current method}

The first and most critical step in the recruitment process is identifying the hiring needs. The key point here is to understand the complete job description in order to clearly state the specifications and qualifications required for the job. This is very important since this document will generate the desired candidate profile and will strongly affect the evaluation and selection steps.

In our case study, the job description is written by the job analyst in the Human Resources (HR) department and Curriculum Vitaes (CV) of applicants are evaluated. According to the evaluation of job analyst, the selected candidates are invited to the company for an interview. In the second step, the candidates are interviewed by a group of experts. It should be noted that all experts in the interview (i.e. the decisionmaking group) have equal weights. These experts can change according to the vacant position. The predetermined questions are asked to the candidates and according to their responses, the decision-makers grade them from one to ten on consensus after the interview. In the end, the arithmetic average is calculated for each candidate and the one with the highest grade is hired for the job.

In our case study, a textile company located in Denizli needed to hire a senior Production Planning Engineer (PPE) and issue a recruitment announcement. This job announcement is based on a general job description and is prepared by a job analyst. So, the description does not consider some key technical skills such as six sigma, lean manufacturing and kaizen manufacturing knowledge and neglects the additional 3 year experience in garment industry. This is because the position requires professional knowledge in garment production and practical experience in quality standards. After preliminary screening by the HR department, ten candidates have been called for interview. A committee of three decision-makers:

- $D M_{1}$ : The supervisor of the production planning department;

- $D M_{2}$ : The human resource manager;

- $D M_{3}$ : The supply chain manager of the company has been formed to conduct the interview and ten different questions have been asked to the candidates.

The score of each candidate for each question after the interview is given in Table 2.

Based on the total scores, $C_{8}$ with the highest total score has been selected for the position. However, this method does not consider the SA of candidates and their interactions with TC. For example, a candidate could have excellent Technical Requirements (TR), but he could not get along with others and has the ability to work in a team. In this case, the person may not work for a long time in that position, and hiring such a person may be a waste of time.

Considering this example, the used current method can be said to be very simple, highly subjective and biased. Furthermore, it includes too much intuitiveness and lacks professionalism. In today system-oriented era, the HR department should create more analytical and robust methodologies for such an important process of companies. In order to deal with these disadvantages of the current method, we propose a more analytical approach in this study. The next section explains the details of the proposed method. 
Table 1. The related literature on Personnel Selection Problem (PSP).

\begin{tabular}{|c|c|c|}
\hline Reference & Method & Application area \\
\hline Jasemi and Ahmadi [20] & Fuzzy ELECTRE & Industrial engineer \\
\hline Samanlioglu et al. [18] & Fuzzy AHP and fuzzy TOPSIS & IT personnel \\
\hline Ji et al. [21] & Fuzzy TODIM with MVNS & Sales supervisor \\
\hline Efe and Kurt [22] & $\begin{array}{l}\text { TOPSIS and interval type- } 2 \text { trapezoidal fuzzy } \\
\text { numbers }\end{array}$ & Personnel for assembly lines \\
\hline Dahooie et al. [23] & SWARA and grey ARAS & IT expert \\
\hline Deliktas and Ustun [24] & $\begin{array}{l}\text { MULTIMOORA and multichoice conic goal } \\
\text { programming }\end{array}$ & Erasmus student \\
\hline Koutra et al. [25] & AHP and correspondence analysis & $\begin{array}{l}\text { Managerial personnel } \\
\text { in the maritime field }\end{array}$ \\
\hline Urosevic et al. [26] & SWARA and WASPAS & Sales manager \\
\hline Bayram and Sahin [36] & Monte Carlo simulation and TOPSIS & General empirical study \\
\hline Kosareva et al. [37] & $\begin{array}{l}\text { Kemeny Median Indicator Rank Accordance } \\
\text { (KEMIRA) }\end{array}$ & Security personnel \\
\hline Karabasevic et al. [27] & SWARA and ARAS & Sales manager \\
\hline Liu et al. [38] & Interval 2-tuple and VIKOR & Healthcare personnel \\
\hline Sang et al. [16] & Fuzzy TOPSIS and Karnik-Mendel algorithm & System analysis engineer \\
\hline Alguliyev et al. [28] & Worst case method and fuzzy VIKOR & PhD student \\
\hline Chang [29] & Fuzzy Delphi, ANP and TOPSIS & Public relations personnel \\
\hline Kazan et al. [11] & AHP and PROMETHEE & Deputy candidate \\
\hline Kusumawardani and Agintiara [17] & Fuzzy AHP and fuzzy TOPSIS & Human resources manager \\
\hline Canós et al. [32] & Software: Staff designer and fuzzy theory & General empirical study \\
\hline Bogdanovic and Miletic [39] & AHP and PROMETHEE & General empirical study \\
\hline Keršulienè and Turskis [40] & AHP and ARAS & Chief accountant \\
\hline Bali et al. [41] & Delphi and fuzzy sets & System analyzer \\
\hline Rouyendegh and Erkan [42] & Fuzzy ELECTRE & Academic staff \\
\hline Aggarwal [43] & AHP and fuzzy linear programming & IT personnel \\
\hline Kabak [33] & Fuzzy DEMATEL and ANP & Military personnel \\
\hline Kabak et al. [44] & Fuzzy ANP, fuzzy TOPSIS and fuzzy ELECTRE & Professional sniper \\
\hline Baležentis et al. [34] & Computing with words and fuzzy MULTIMOORA & General empirical study \\
\hline Safarzadegan Gilan et al. [45] & Computing with words and interval type 2 fuzzy set & Construction personnel \\
\hline Boran et al. [15] & Fuzzy TOPSIS & Sales manager \\
\hline Kelemenis et al. [46] & Extended fuzzy TOPSIS & Support manager \\
\hline Zhang and Liu [1] & GRA and fuzzy IFWA & System analysis engineer \\
\hline $\operatorname{Lin}[3]$ & ANP and fuzzy DEA & Electrical engineer \\
\hline Dağdeviren [35] & TOPSIS and ANP & Electronics engineer \\
\hline Dursun and Karsak [5] & 2-tuple linguistic representation model and TOPSIS & General empirical study \\
\hline Kelemenis and Askounis [14] & Fuzzy TOPSIS & Management team member \\
\hline Güngör et al. [9] & Fuzzy AHP & General empirical study \\
\hline Chien and Chen [30] & Data mining (decision tree and association rules) & General empirical study \\
\hline Chen and Cheng [31] & GDSS based on metric distance method & IT personnel \\
\hline
\end{tabular}


Table 2. Scores of each candidate for each question.

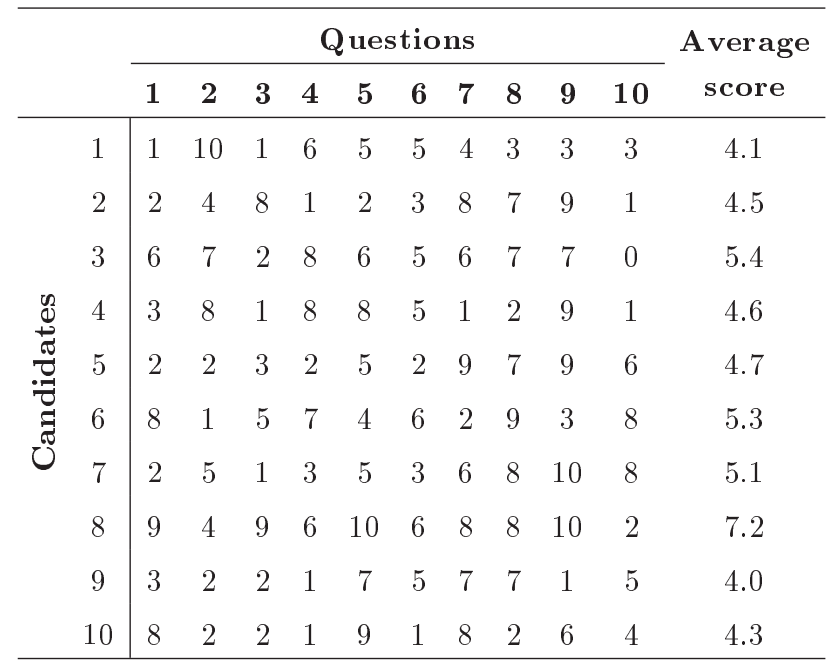

\section{The proposed method}

The developed decision-making framework utilizes the methodologies of DEMATEL, QFD, and GRA for PSP. In order to capture the inherited vagueness, fuzzy set theory and group decision-making approaches have also been adopted. The proposed framework consists of five steps including fuzzy DEMATEL, fuzzy QFD and fuzzy GRA. In all steps, triangular fuzzy numbers, which generally considered an easy and effective way to quantify linguistic judgments of decision-makers, are utilized. In addition to vagueness and fuzziness, the group decisionmaking process, which enables the gradation of the criteria and the alternatives by three decision-makers, has been adopted. First, the fuzzy DEMATEL method has been used for weighting the SA which are then used as inputs for the following step. The weights of the TR are calculated by applying the fuzzy QFD method, which can evaluate the interrelationships and the correlation of social and technical criteria. Finally, the fuzzy GRA method has been applied to rank the alternatives. The stepwise schematic representation of the proposed integrated method is depicted in Figure 1.

Each step of the proposed method is explained in the following:

Step 1: Identifying the feature that the candi-

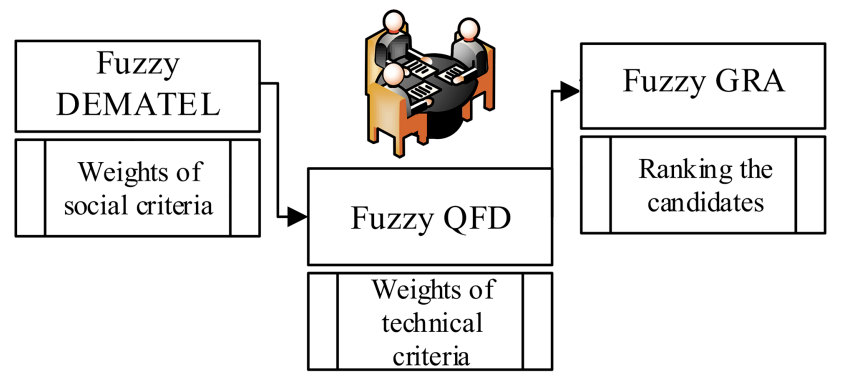

Figure 1. The schematic representation of the proposed method. date should have internal variables "WHATs" in order to satisfy the company's needs. The first step of the proposed method starts with identifying the features of the candidate in order to satisfy the company's needs. These are the internal variables "WHATs". It should be noted that these internal variables are Social Criteria $(\mathrm{SC})$;

Step 2: Identifying the relevant TR (external variables "HOWs"). Regarding the position, TR should be defined. These are called external variables "HOWs". It should be noted that these external variables are TC;

Step 3: Weighting the "WHATs". The third step determines the weights of the internal variables using fuzzy DEMATEL. DEMATEL method derived from graph theory was developed by Gabus and Fontela at the Geneva Research Center of the Battelle Memorial Institute [47]. It has been widely recognized as an effective method to reveal interrelationships between criteria and to identify the hierarchical structure of models. It is also considered to be an important tool to visualize the cause and effect relationships between complex factors [48]. To cope with the uncertainties, fuzzy DEMATEL has been widely preferred recently. There are a lot of applications of the fuzzy DEMATEL approach in various MCDM problems such as supplier selection [49], bidder evaluation [50], comparison of service quality improvement strategies [51], evaluation of critical operational hazards [48], project portfolio selection [52], resilience supplier selection [53]. In order to deal with the uncertainties, we also have utilized fuzzy DEMATEL. The outputs of this step have been used as inputs for the fourth step. The steps of fuzzy DEMATEL are given in Appendix A;

Step 4: Constructing the House Of Quality (HOQ). HOQ is a matrix that is commonly used in the evaluation and selection process in QFD. QFD is a method developed by Akao [54], which allows to systematically transform the qualitative needs of customers into quantitative quality characteristics in the decision-making stage of new product development. A well-structured, cross-functional technique that takes into account customer needs can ensure higher quality standards to meet expectations. Although the QFD method was introduced to deal with quality problems at each stage of the entire planning process, it has been widely used as an effective tool for evaluating various alternatives in recent years. QFD method used in product design process consists of four matrices, namely, the customer requirementplanning matrix, the product characteristics deployment matrix, process and quality control matrix and operative instruction matrix [55]. However, only the 


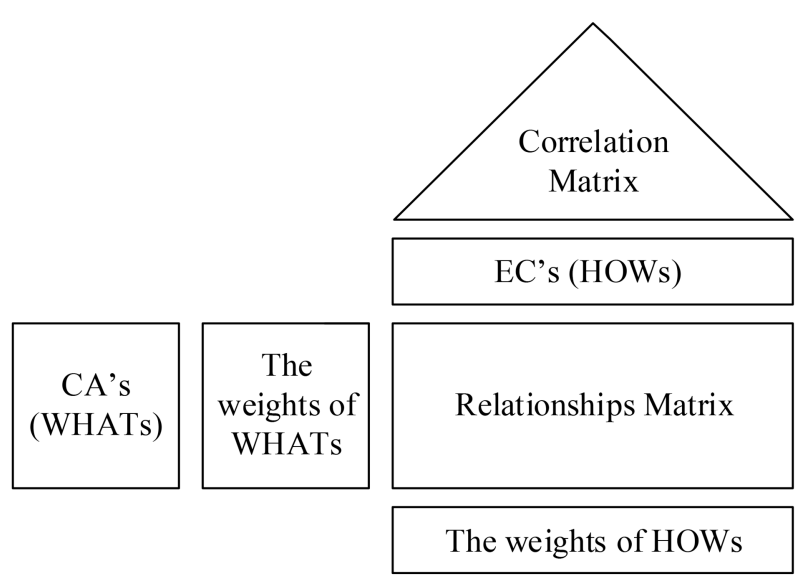

Figure 2. The general representation of House Of Quality (HOQ).

first matrix, also called HOQ, has been commonly practiced in the evaluation and selection process.

In this step, HOQ which translates customer needs and requirements (customer attributesCA's-WHATs) into product design or TR, process planning, and production needs (engineering characteristics-EC's-HOWs), has been constructed. The key feature of the matrix is to take cognizance of the voice of the customer and to reveal the customer requirements in the end. A general HOQ model is illustrated in Figure 2 including the following:

- CA (WHATs), which are generally qualitative, includes requests and needs related to customerdefined product or service characteristics and known as the voice of the customer;

- EC (HOWs), which are generally quantitative, contain determining the technical requirements to meet customer requests and needs and are known as the voice of the company;

- The weights of WHATs show the importance of the related requirement and used to prioritize the CA's;

- Relationships between WHATs and HOWs; the relationships matrix indicates the degree of influence of each CA on each EC;

- The correlation matrix, which is used to show the inner dependence relations among ECs, is known as the roof matrix;

- The weights of HOWs, which are the major output of the HOQ, show the final importance scores of HOWs and are known as the ratings of EC.

In this study, the conceptual approach of the HOQ remained unchanged, while the components have been translated: in the conventional method, the company has to conceive its customers' needs and their importance degrees (CA) to determine which EC should be allocated the most resources [56]; on the other hand, in MCDM context, specifically

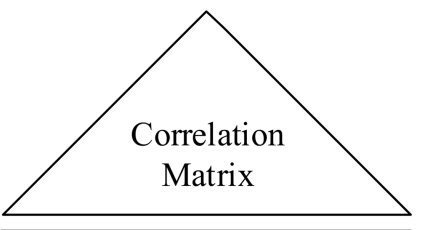

Technical Requirements (TR)
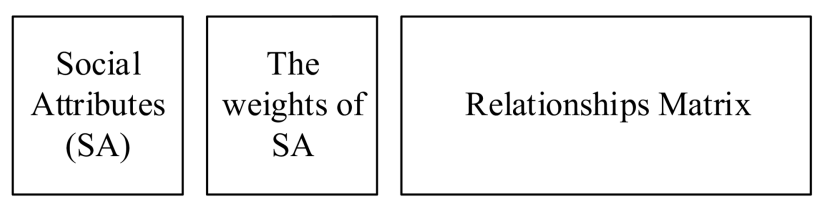

The weights of TR
Figure 3. The House Of Quality (HOQ) representation of the proposed Quality Function Deployment (QFD) method.

PSP, the company defines the SA required for the candidate to obtain the weights of the TR. Within this scope, the components of the HOQ, namely SC, $\mathrm{TC}$, relationships matrix, correlation matrix, and weights of the criteria, are shown in Figure 3.

The details of the fuzzy QFD can be found in Appendix B.

Step 5: Ranking the candidates. After obtaining the weights of the criteria considered in the problem, the candidates are ranked using fuzzy GRA. GRA is a MCDM method, which is evolved from the grey system theory proposed by Liu et al. [57]. The starting point of this method is to visualize the level of knowledge in any situation through a color scale, ranging between white and black. Black represents absolute uncertainty, while white represents the highest level of knowledge without any ambiguity. The most suitable color to represent real-world cases is considered grey. In this content, GRA allows the relationship between different factors to be expressed mathematically, and the interactions between factors are complicated [58]. The advantages of this method include ease of use, the possibility of using qualitative and quantitative data, and the applicability of the solution to small data sets. In recent years, GRA has been widely used in different applications such as green supplier selection in the agri-food industry [59], personnel selection [1], service quality evaluation of airports [58], and optimization of bone drilling process parameters [60], crew scheduling [61]. The steps of fuzzy GRA are explained in Appendix C in detail.

\section{The case study}

In this section, the application of the proposed approach is illustrated by the same case study that has already been explained in Section 3. However, here 
the job description and weights of decision-makers have changed. Since the position is to hire a PPE, the weight of $D M_{1}$ (the supervisor of the production planning department) has been assigned to 0.5, while the weights of other decision-makers, $D M_{2}$ (human resources manager) and $D M_{3}$ (supply chain manager), have been set to 0.25 for final evaluation. The job description has been reprepared with the supervisor of the production planning manager and now considers some key technical skills such as six sigma, lean manufacturing, and kaizen manufacturing knowledge, and quality standards. Based on the new job description, the committee has decided to evaluate five candidates $\left(C_{3}, C_{4}, C_{5}, C_{6}\right.$, and $\left.C_{8}\right)$. It should be noted that $C_{1}, C_{2}, C_{7}, C_{9}$, and $C_{10}$ have not been evaluated in the proposed approach since they do not satisfy the requirements of the new job description.

\subsection{Defining WHATs and HOWs}

As a result of discussions with the committee members and the assessment gathered through the literature review, the $\mathrm{SC}$ and $\mathrm{TC}$ of the required personnel have been identified. We classify SC as WHATs, i.e. the features that the candidate should have to satisfy the company needs, and TC as HOWs, i.e. the features that each candidate has. These selection criteria are listed in Tables 3 and 4, respectively.

\subsection{Determining the weights of WHATs}

After determining the WHATs and HOWs, the fuzzy DEMATEL method has been employed to determine the weights of the WHATs, i.e. the weights of SC.

Each decision-maker has been asked to compare the SC. According to feedbacks, the decision matrix has been constructed using linguistic terms such as very low

Table 3. Social criteria (WHATs).

\begin{tabular}{ll}
\hline$S C_{1}$ & Oral communication skills \\
$S C_{2}$ & References \\
$S C_{3}$ & Team work \\
$S C_{4}$ & Self-confidence and leadership \\
$S C_{5}$ & Emotional steadiness \\
$S C_{6}$ & Responsibility \\
$S C_{7}$ & Self-motivation \\
\hline
\end{tabular}

Table 4. Technical criteria (HOWs).

\begin{tabular}{ll}
\hline$T C_{1}$ & Educational background \\
$T C_{2}$ & Foreign language skills \\
$T C_{3}$ & Basic computer skills \\
$T C_{4}$ & Work experience \\
$T C_{5}$ & Decision-making skills \\
$T C_{6}$ & Risk management skills \\
\hline
\end{tabular}

Table 5. The linguistic scale [62].

\begin{tabular}{lc}
\hline $\begin{array}{c}\text { Description } \\
\text { (effect) }\end{array}$ & $\begin{array}{c}\text { Triangular } \\
\text { fuzzy number }\end{array}$ \\
\hline No (N) & $(0,0,0.25)$ \\
Very Low (VL) & $(0,0.25,0.5)$ \\
Low (L) & $(0.25,0.5,0.75)$ \\
High (H) & $(0.5,0.75,1)$ \\
Very High (VH) & $(0.75,1,1)$ \\
\hline
\end{tabular}

and low. Then it is transferred to the fuzzy number. Transformation of linguistic terms into fuzzy numbers is carried out by using the widely accepted linguistic scale for the DEMATEL method introduced by $\mathrm{Li}$ [62]. The linguistic scale is shown in Table 5.

The decision matrix, which consists of pairwise comparison values of decision-makers, $D M_{1}$ to $D M_{3}$ in sequence, is shown in Table 6 .

After constructing the decision matrix for each decision-maker, linguistic expressions have been transformed into triangular fuzzy numbers. In the following step, the aggregate decision matrix has been obtained by multiplying the weights of decision-makers by fuzzy expressions. The normalized aggregate decision matrix and the total relation matrix have been obtained from the aggregate decision matrix. The next step includes transforming fuzzy triangular numbers into crisp values by adopting the defuzzification process proposed by Opricovic and Tzeng [63]. $D_{i}$ and $R_{i}$ values are calculated by summation values of rows and columns. The data set of causal diagrams that represents the influence levels via $D_{i}, R_{i}, D_{i}+R_{i}$, and $D_{i}-R_{i}$ values is shown in Table 7 . The weights of the $\mathrm{SC}$ are given in Table 8.

From Table $8, S C_{7}$ self-motivation criteria are considered as the most important criterion followed by $S C_{5}$ emotional steadiness and $S C_{4}$ self-confidence and leadership, respectively.

\subsection{Determining the weights of $\mathrm{HOWs}$}

In the next step, QFD has been utilized to obtain the weights of HOWs, i.e. TC. QFD method allows the use of HOQ to consider the relationships between $\mathrm{SC}$ and TC and interrelationships between TC. The weights of the $\mathrm{SC}$ obtained in the previous step have been incorporated into $\mathrm{TC}$ of the decision-making process in this step.

Firstly, the relationships and correlation matrices are constructed through an interview with the decisionmakers. For the assessment of relationships and correlation matrices, the linguistic scales introduced by Bottani and Rizzi [55] given in Tables 9 and 10, respectively, have been adopted.

The relationships and correlation matrices are shown in Figure 4. 
Table 6. The decision matrix regarding the criteria.

\begin{tabular}{|c|c|c|c|c|c|c|c|}
\hline & $S C_{1}$ & $S C_{2}$ & $S C_{3}$ & $S C_{4}$ & $S C_{5}$ & $S C_{6}$ & $S C_{7}$ \\
\hline$S C_{1}$ & 0 & $\mathrm{~L}, \mathrm{~L}, \mathrm{VL}$ & VH,VL,H & $\mathrm{H}, \mathrm{VL}, \mathrm{L}$ & $\mathrm{L}, \mathrm{VL}, \mathrm{VL}$ & $\mathrm{N}, \mathrm{N}, \mathrm{N}$ & $\mathrm{N}, \mathrm{VL}, \mathrm{N}$ \\
\hline$S C_{2}$ & $\mathrm{~N}, \mathrm{~N}, \mathrm{~N}$ & 0 & $\mathrm{~N}, \mathrm{~N}, \mathrm{~N}$ & $\mathrm{~N}, \mathrm{VL}, \mathrm{VL}$ & $\mathrm{N}, \mathrm{N}, \mathrm{N}$ & $\mathrm{N}, \mathrm{N}, \mathrm{N}$ & VL, VL, VL \\
\hline$S C_{3}$ & N,VL,L & $\mathrm{N}, \mathrm{L}, \mathrm{L}$ & 0 & $\mathrm{~L}, \mathrm{VL}, \mathrm{VL}$ & $\mathrm{L}, \mathrm{VL}, \mathrm{VL}$ & $\mathrm{L}, \mathrm{VL}, \mathrm{L}$ & $\mathrm{L}, \mathrm{VL}, \mathrm{VL}$ \\
\hline$S C_{4}$ & $\mathrm{~N}, \mathrm{~L}, \mathrm{VL}$ & $\mathrm{N}, \mathrm{L}, \mathrm{VL}$ & $\mathrm{L}, \mathrm{VL}, \mathrm{L}$ & 0 & $\mathrm{~L}, \mathrm{VL}, \mathrm{L}$ & $\mathrm{L}, \mathrm{L}, \mathrm{N}$ & $\mathrm{H}, \mathrm{VL}, \mathrm{H}$ \\
\hline$S C_{5}$ & $\mathrm{H}, \mathrm{L}, \mathrm{H}$ & $\mathrm{L}, \mathrm{N}, \mathrm{L}$ & $\mathrm{H}, \mathrm{N}, \mathrm{VL}$ & H,VL,VL & 0 & $\mathrm{H}, \mathrm{N}, \mathrm{VL}$ & Н,Н,H \\
\hline$S C_{6}$ & $\mathrm{~L}, \mathrm{~N}, \mathrm{VL}$ & $\mathrm{H}, \mathrm{L}, \mathrm{H}$ & $\mathrm{H}, \mathrm{H}, \mathrm{VL}$ & $\mathrm{L}, \mathrm{L}, \mathrm{VL}$ & $\mathrm{L}, \mathrm{VL}, \mathrm{N}$ & 0 & $\mathrm{H}, \mathrm{VL}, \mathrm{L}$ \\
\hline$S C_{7}$ & $\mathrm{H}, \mathrm{VL}, \mathrm{VL}$ & H,H,H & $\mathrm{H}, \mathrm{L}, \mathrm{L}$ & $\mathrm{H}, \mathrm{L}, \mathrm{L}$ & H,VL,L & $\mathrm{L}, \mathrm{VL}, \mathrm{L}$ & 0 \\
\hline
\end{tabular}

Table 7. The influence levels among criteria.

\begin{tabular}{cccccl}
\hline Criteria & $\boldsymbol{D}_{\boldsymbol{i}}$ & $\boldsymbol{R}_{\boldsymbol{i}}$ & $\boldsymbol{D}_{\boldsymbol{i}}+\boldsymbol{R}_{\boldsymbol{i}}$ & $\boldsymbol{D}_{\boldsymbol{i}}-\boldsymbol{R}_{\boldsymbol{i}}$ & Group \\
\hline$S C_{1}$ & 5.143 & 4.868 & 10.011 & 0.275 & Cause \\
$S C_{2}$ & 2.342 & 6.201 & 8.543 & -3.858 & Effect \\
$S C_{3}$ & 5.269 & 6.318 & 11.587 & -1.049 & Effect \\
$S C_{4}$ & 5.878 & 6.007 & 11.886 & -0.129 & Effect \\
$S C_{5}$ & 7.174 & 5.205 & 12.379 & 1.970 & Cause \\
$S C_{6}$ & 6.380 & 4.715 & 11.096 & 1.665 & Cause \\
$S C_{7}$ & 7.189 & 6.062 & 13.252 & 1.127 & Cause \\
\hline
\end{tabular}

Since there are three decision-makers, the importance (i.e. weights) of these decision-makers has been considered in obtaining the aggregate relationships and correlation matrices using a weighted average. By adding the aggregate correlation values of the criteria, the weights of the TC are acquired. After the defuzzification process proposed by Yager [64], the weights of TC are shown in Table 11.

\subsection{Ranking the candidates}

In the last step of the proposed integrated method, fuzzy GRA has been employed to determine the most appropriate candidate for the job. It should be noted that with the proposed approach five candidates (i.e. $C_{3}, C_{4}, C_{5}, C_{6}$, and $C_{8}$ ) have been evaluated.

Initially, the decision matrix showing the evaluation scores of candidates based on TC has been constructed by each decision-maker. Since it is easier to use linguistic terms in comparisons and evaluations, the
Table 9. The linguistic scale for relationships matrix [55].

\begin{tabular}{lc}
\hline $\begin{array}{c}\text { Degree of } \\
\text { relationship }\end{array}$ & $\begin{array}{c}\text { Fuzzy triangular } \\
\text { number }\end{array}$ \\
\hline Strong $(\mathrm{S})$ & $(0.7,1,1)$ \\
Medium $(\mathrm{M})$ & $(0.3,0.5,0.7)$ \\
Weak $(\mathrm{W})$ & $(0,0,0.3)$ \\
No $(\mathrm{N})$ & $(0,0,0)$ \\
\hline
\end{tabular}

Table 10. The linguistic scale for correlation matrix [55].

\begin{tabular}{lc}
\hline \multicolumn{1}{c}{$\begin{array}{c}\text { Degree of } \\
\text { correlation }\end{array}$} & $\begin{array}{c}\text { Fuzzy triangular } \\
\text { number }\end{array}$ \\
\hline Strong Positive (SP) & $(0.7,1,1)$ \\
Positive (P) & $(0.5,0.7,1)$ \\
Negative (N) & $(0,0.3,0.5)$ \\
Strong Negative (SN) & $(0,0,0.3)$ \\
No $(-)$ & $(0,0,0)$ \\
\hline
\end{tabular}

Table 11. The weights of technical criteria.

\begin{tabular}{lcccccc}
\hline \multicolumn{1}{c}{ Criteria } & $\boldsymbol{T C}_{\boldsymbol{1}}$ & $\boldsymbol{T C}_{\boldsymbol{2}}$ & $\boldsymbol{T} \boldsymbol{C}_{\boldsymbol{3}}$ & $\boldsymbol{T} \boldsymbol{C}_{\boldsymbol{4}}$ & $\boldsymbol{T} \boldsymbol{C}_{\boldsymbol{5}}$ & $\boldsymbol{T} \boldsymbol{C}_{\boldsymbol{6}}$ \\
\hline Weight & 0.483 & 0.191 & 0.454 & 1.047 & 1.007 & 0.933 \\
Normalized & 0.117 & 0.046 & 0.110 & 0.255 & 0.245 & 0.227 \\
weight & & & & & & \\
\hline
\end{tabular}

decision matrix has been constructed using linguistic terms and then converted to triangular fuzzy numbers using the linguistic scale proposed by Kulak and Kahraman [65] shown in Table 12.

Table 8. The weights of social criteria.

\begin{tabular}{lccccccc}
\hline \multicolumn{1}{c}{ Criteria } & $\boldsymbol{S C}_{\mathbf{1}}$ & $\boldsymbol{S C}_{\mathbf{2}}$ & $\boldsymbol{S \boldsymbol { C } _ { \mathbf { 3 } }}$ & $\boldsymbol{S C}_{\boldsymbol{4}}$ & $\boldsymbol{S \boldsymbol { C } _ { \mathbf { 5 } }}$ & $\boldsymbol{S} \boldsymbol{C}_{\boldsymbol{6}}$ & $\boldsymbol{S C}_{\boldsymbol{7}}$ \\
\hline Weight & 10.015 & 9.374 & 11.635 & 11.886 & 12.535 & 11.220 & 13.299 \\
Normalized weight & 0.125 & 0.117 & 0.146 & 0.149 & 0.157 & 0.140 & 0.166 \\
\hline
\end{tabular}




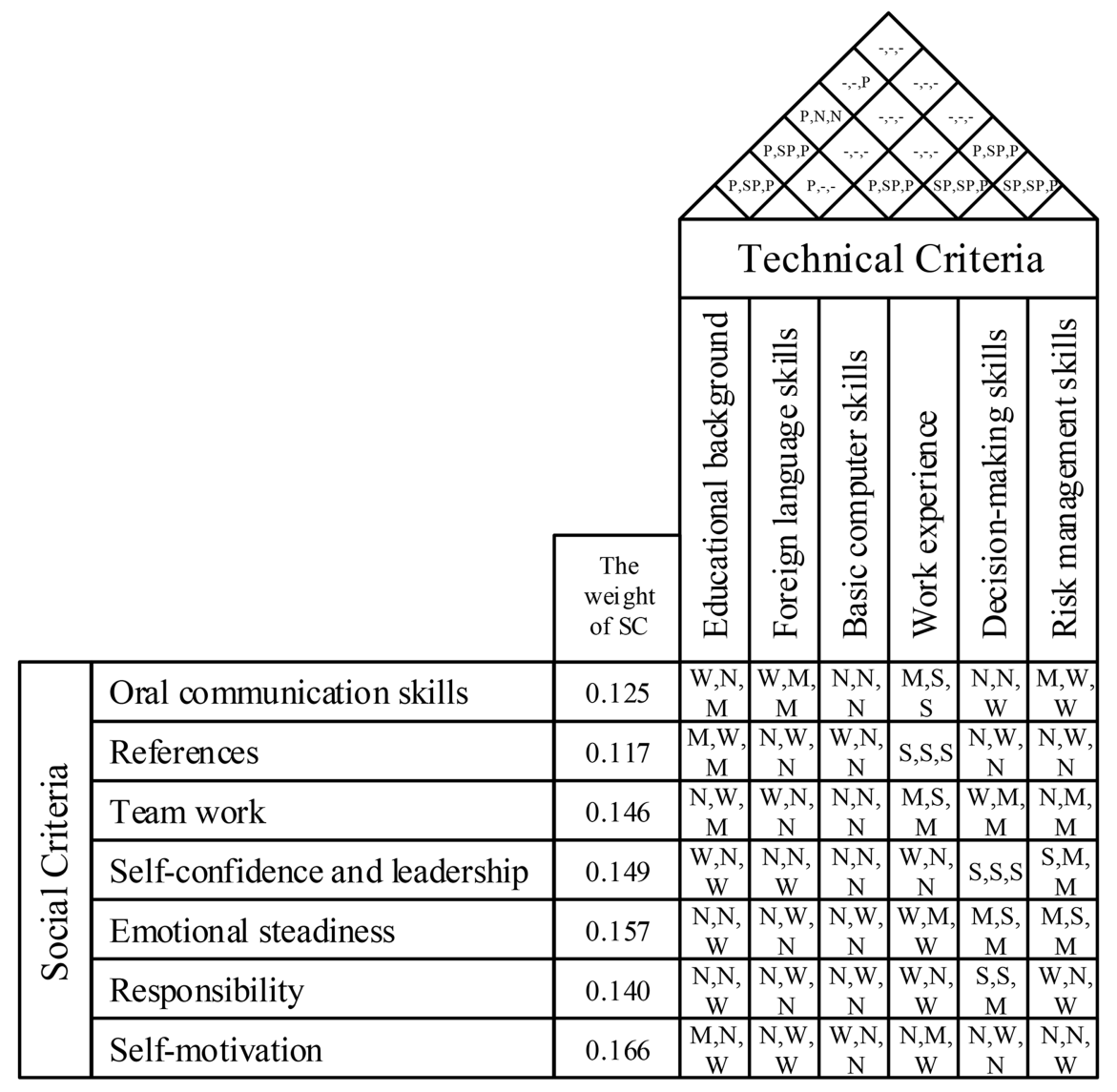

Figure 4. The relationships and correlation matrices.

Table 12. The linguistic scale [65].

\begin{tabular}{lc}
\hline Alternative ratings & Triangular fuzzy number \\
\hline Poor (P) & $(0,0,6)$ \\
Fair (F) & $(4,7,10)$ \\
Good (G) & $(8,11,14)$ \\
Very Good (VG) & $(12,15,18)$ \\
Excellent (E) & $(16,20,20)$ \\
\hline
\end{tabular}

The aggregate decision matrix that represents the assessment scores of the candidates is shown in Table 13.

Once the aggregate decision matrix is formed, the normalized aggregate decision matrix has been obtained based on the objective. The values closest to the most ideal score establish the reference series. Then, by using reference series, the distance matrix is formed. By using grey relational coefficients as the elements of the grey relational grades matrix, the final evaluation scores of the candidates are calculated and shown in Table 14.

As shown in Table 13, the person most suitable for the position is the fourth person with the highest evaluation score. A comparative ranking of the alternative candidates is obtained as $C_{3}>C_{4}>C_{8}>C_{6}>C_{5}$ when scores are arranged in descending order.

\section{Discussion}

As we compared the results of the current method used by the company and the proposed method, two different results have been obtained. The proposed approach states that the third candidate should be hired for the position although the eighth has been selected in the current approach. This could be the interactions among criteria considered in the evaluation phase and the detailed job description. The main drawback of the current method used by the company is that the description of a job has been defined by a job analyst. Although the job analyst can perfectly define the job, he/she cannot define all technical details. For some positions that do not require special expertise, this may be acceptable, but it may cause serious problems in key positions in the company. Therefore, it would be a big mistake to completely exclude the supervisor/manager from the job description, because the supervisor/manager has a wealth of knowledge and understands the key responsibilities and skills of the job. The incomplete definition of a job could lead to hiring a wrong person which could affect the 
Table 13. The aggregate decision matrix.

\begin{tabular}{ccccccc}
\hline & $\boldsymbol{T C}_{\mathbf{1}}$ & $\boldsymbol{T} \boldsymbol{C}_{\mathbf{2}}$ & $\boldsymbol{T} \boldsymbol{C}_{\mathbf{3}}$ & $\boldsymbol{T} \boldsymbol{C}_{\boldsymbol{4}}$ & $\boldsymbol{T} \boldsymbol{C}_{\mathbf{5}}$ & $\boldsymbol{T} \boldsymbol{C}_{\mathbf{6}}$ \\
\hline$C_{3}$ & F,F,P & F,F,F & G,G,F & VG,E,VG & VG,G,E & VG,VG,E \\
$C_{4}$ & VG,E,VG & VG,E,VG & E,VG,VG & F,F,G & G,G,VG & G,G,VG \\
$C_{5}$ & G,VG,G & E,E,VG & VG,VG,VG & F,F,P & G,G,VG & F, G,F \\
$C_{6}$ & E,VG,E & VG,VG,G & VG,G,VG & F,G,F & F, G,G & F,F,G \\
$C_{8}$ & G,G,F & G,VG,G & G,G,G & G,G,G & VG,G,VG & G,G,F \\
\hline
\end{tabular}

Table 14. The final evaluation scores.

\begin{tabular}{lccccc}
\hline Candidates & $\boldsymbol{C}_{\mathbf{3}}$ & $\boldsymbol{C}_{\boldsymbol{4}}$ & $\boldsymbol{C}_{\mathbf{5}}$ & $\boldsymbol{C}_{\boldsymbol{6}}$ & $\boldsymbol{C}_{\mathbf{8}}$ \\
\hline Score & 0.833 & 0.634 & 0.534 & 0.538 & 0.586 \\
Ranking & 1 & 2 & 5 & 4 & 3 \\
\hline
\end{tabular}

organization. Therefore, the group decision-making method should consider the opinions of the department manager at the end and in the initial steps of the recruitment process.

To overcome this shortcoming, in this paper, we suggest that the job description should be jointly developed by the HR department and the technical supervisor/manager. This would also let us considering both technical and SC of candidates in the selection process. Taking into account the interactions and opinions of different people, the proposed approach is a robust analytical method for the HR department. Moreover, since the proposed approach considers the TR of the job, the number of candidates that should be evaluated decreases which saves the amount of time needed.

\section{Conclusions}

Selecting the most appropriate person for the job is a serious and important challenge in human resource systems. There are many attempts in the literature to help practitioners to select the right person for the right job and we believe that further applications of new methodologies in this field will be developed.

The method proposed in this paper is mainly distinguished from other methods by combining two Multi-Criteria Decision-Making (MCDM) methods with Quality Function Deployment (QFD). The motivation behind this procedure is to help the human resources department to form and prioritize internal and external parameters., a robust decision structure to select the most appropriate candidate for the defined job. To better understand and to compare the proposed method with the method currently used by the company, it has been simulated through real case studies. In view of this, the applications of the production planning engineer are evaluated by a group of decision makers. Social criteria and technical criteria are determined to predict the job performance of the candidates. Every decision-maker has their own opinion and sometimes there may be conflicts between them, as shown in the table above. First of all, social criteria and their complex inter-relational structure have been analyzed by Decision-Making Trial and Evaluation Laboratory (DEMATEL) and then the technical criteria of the job have been considered and integrated with social criteria so that the ideal candidate that satisfies not only social but also technical criteria, can be selected. Human intuition prefers to use language variables instead of numbers, so fuzzy logic has been integrated into the model. In the ranking of outputs, fuzzy Gray Relationship Analysis (GRA) method has been chosen since it is very efficient in this field.

Finally, it is expected that this comprehensive approach will become a useful tool for human resource management, reducing employee turnover and recruitment, and making the organization more competitive and efficient.

In the future, to incorporate uncertainty into decision-making process, some new aggregation operators under the uncertain environment can be added to the decision framework [66-70].

\section{References}

1. Zhang, S-F. and Liu, S-Y. "A GRA-based intuitionistic fuzzy multi-criteria group decision making method for personnel selection", Expert Systems with Applications, 38(9), pp. 11401-11405 (2011).

2. Liao, S.K. and Chang, K.L. "Selecting public relations personnel of hospitals by analytic network process", Journal of Hospital Marketing and Public Relations, 19(1), pp. 52-63 (2009).

3. Lin, H.T. "Personnel selection using analytic network process and fuzzy data envelopment analysis approaches", Computers and Industrial Engineering, 59(4), pp. 937-944 (2010).

4. Zadeh, L.A. "Fuzzy sets", Information and Control, 8(3), pp. 338-353 (1965).

5. Dursun, M. and Karsak, E.E. "A fuzzy MCDM approach for personnel selection", Expert Systems with Applications, 37(6), pp. 4324-4330 (2010).

6. Afshari, A.R., Nikolić, M., and Ćoćkalo, D. "Applications of fuzzy decision making for personnel selection problem - A review", Journal of Engineering Management and Competitiveness, 4(2), pp. 68-77 (2014). 
7. Petrovic-Lazarevic, S. "Personnel selection fuzzy model", International Transactions in Operational Research, 8(1), pp. 89-105 (2001).

8. Özgörmüş, E., Mutlu, Ö., and Güner, H. "Bulanık AHP ile personel seçimi", 5th Ulusal Üretim Araştırmaları Sempozyumu, Istanbul, Turkey, pp. 111115 (2005).

9. Güngör, Z., Serhadlioglu, G., and Kesen, S.E. "A fuzzy AHP approach to personnel selection problem", Applied Soft Computing, 9(2), pp. 641-646 (2009).

10. Chen, P.C. "A fuzzy multiple criteria decision making model in employee recruitment", International Journal of Computer Science and Network Security, 9(7), pp. 113-117 (2009).

11. Kazan, H., Özçelik, S., and Haykir Hobikoğlu, E. "Election of deputy candidates for nomination with AHP-PROMETHEE methods", Procedia-Social and Behavioral Sciences, 195, pp. 603-613 (2015).

12. Ayub, M., Kabir, M.J., and Alam, M.G.R. "Personnel selection method using Analytic Network Process (ANP) and fuzzy concept", 12th International Conference on Computers and Information Technology, Dhaka, Bangladesh, pp. 373-378 (2009).

13. Chen, C.T. "Extensions of the TOPSIS for group decision-making under fuzzy environment", Fuzzy Sets and Systems, 114(1), pp. 1-9 (2000).

14. Kelemenis, A. and Askounis, D. "A new TOPSISbased multi-criteria approach to personnel selection", Expert Systems with Applications, 37(7), pp. 49995008 (2010).

15. Boran, F.E., Genç, S., and Akay, D. "Personnel selection based on intuitionistic fuzzy sets", Human Factors and Ergonomics in Manufacturing and Service Industries, 21(5), pp. 493-503 (2011).

16. Sang, X., Liu, X., and Qin, J. "An analytical solution to fuzzy TOPSIS and its application in personnel selection for knowledge-intensive enterprise", Applied Soft Computing, 30, pp. 190-204 (2015).

17. Kusumawardani, R.P. and Agintiara, M. "Application of fuzzy AHP-TOPSIS method for decision making in human resource manager selection process", Procedia Computer Science, 72, pp. 638-646 (2015).

18. Samanlioglu, F., Taskaya, Y.E., Gulen, U.C., et al. "A fuzzy AHP-TOPSIS-based group decision-making approach to IT personnel selection", International Journal of Fuzzy Systems, 20(5), pp. 1576-1591 (2018).

19. Hashemi, S.H., Karimi, A., and Tavana, M. "An integrated green supplier selection approach with analytic network process and improved grey relational analysis", International Journal of Production Economics, 159, pp. 178-191 (2015).

20. Jasemi, M. and Ahmadi, E. "A new fuzzy ELECTREbased multiple criteria method for personnel selection", Scientia Iranica, 25(2), pp. 943-953 (2018).

21. Ji, P., Zhang, H.Y., and Wang, J.Q. "A projectionbased TODIM method under multi-valued neutrosophic environments and its application in personnel selection", Neural Computing and Applications, 29(1), pp. 221-234 (2018).

22. Efe, B. and Kurt, M. "A systematic approach for an application of personnel selection in assembly line balancing problem", International Transactions in $O p$ erational Research, 25, pp. 1001-1025 (2018).

23. Dahooie, J.H., Abadi, E.B.J., Vanaki, A.S., et al. "Competency-based IT personnel selection using a hybrid SWARA and ARAS-G methodology", Human Factors and Ergonomics in Manufacturing \& Service Industries, 28, pp. 5-16 (2018).

24. Deliktas, L. and Ustun, O. "Student selection and assignment methodology based on fuzzy MULTIMOORA and multichoice goal programming", International Transactions in Operations Research, 24, pp. 1173-1195 (2017).

25. Koutra, G., Barbounaki, S., Kardaras, D., et al. "A multicriteria model for personnel selection in maritime industry in Greece", IEEE 19th Conference on Business Informatics (CBI), Thessaloniki, Greece, pp. 287294 (2017).

26. Urosevic, S., Karabasevic, D., Stanujkic, D., et al. "An approach to personnel selection in the tourism industry based on the SWARA and the WASPAS methods", Economic Computation and Economic Cybernetics Studies and Research, 51(1), pp. 75-81 (2017).

27. Karabasevic, D., Zavadskas, E.K., Turskis, Z., et al. "The framework for the selection of personnel based on the SWARA and ARAS methods under uncertainties", Informatica, 27(1), pp. 49-65 (2016).

28. Alguliyev, R.M., Aliguliyev, R.M., and Mahmudova, R.S. "Multi-criteria personnel selection by the modified fuzzy VIKOR method", The Scientific World Journal, 2015, pp. 1-16 (2015).

29. Chang, K.L. "The use of a hybrid MCDM model for public relations personnel selection", Informatica, 26(3), pp. 389-406 (2015).

30. Chien, C.F. and Chen, L.F. "Data mining to improve personnel selection and enhance human capital: A case study in high-technology industry", Expert Systems with Applications, 34(1), pp. 280-290 (2008).

31. Chen, L.S. and Cheng, C.H. "Selecting IS personnel use fuzzy GDSS based on metric distance method", European Journal of Operational Research, 160(3), pp. 803-820 (2005).

32. Canós, L., Casasús, T., Liern, V., et al. "Soft computing methods for personnel selection based on the valuation of competences", International Journal of Intelligent Systems, 29(12), pp. 1079-1099 (2014).

33. Kabak, M. "A fuzzy DEMATEL-ANP based multi criteria decision making approach for personnel selection", Journal of Multiple-Valued Logic and Soft Computing, 20(5/6), pp. 571-593 (2013).

34. Baležentis, A., Baležentis, T., and Brauers, W.K.M. "Personnel selection based on computing with words and fuzzy MULTIMOORA", Expert Systems with Applications, 39(9), pp. 7961-7967 (2012). 
35. Dağdeviren, M. "A hybrid multi-criteria decisionmaking model for personnel selection in manufacturing systems", Journal of Intelligent Manufacturing, 21(4), pp. 451-460 (2010).

36. Bayram, H. and Sahin, R. "A simulation based multiattribute group decision making technique with decision constraints", Applied Soft Computing, 49, pp. 629-640 (2016).

37. Kosareva, N., Zavadskas, E.K., Krylovas, A., et al. "Personnel ranking and selection problem solution by application of KEMIRA method", International Journal of Computers Communications and Control, 11(1), pp. 51-66 (2016).

38. Liu, H.C., Qin, J.T., Mao, L.X., et al. "Personnel selection using interval 2-tuple linguistic VIKOR method", Human Factors and Ergonomics in Manufacturing and Service Industries, 25(3), pp. 370-384 (2015).

39. Bogdanovic, D. and Miletic, S. "Personnel evaluation and selection by multicriteria decision making method", Economic Computation and Economic Cybernetics Studies and Research, 48(3), pp. 179-196 (2014).

40. Keršulienè, V. and Turskis, Z. "An integrated multicriteria group decision making process: Selection of the chief accountant", Procedia-Social and Behavioral Sciences, 110, pp. 897-904 (2014).

41. Bali, O., Gümüş, S., and Dağdeviren, M. "A group MADM method for personnel selection problem using Delphi technique based on intuitionistic fuzzy sets", Journal of Military and Information Science, 1(1), pp. 1-13 (2013).

42. Rouyendegh, B.D. and Erkan, T.E. "An application of the fuzzy electre method for academic staff selection", Human Factors and Ergonomics in Manufacturing \& Service Industries, 23(2), pp. 107-115 (2013).

43. Aggarwal, R. "Selection of IT Personnel through Hybrid Multi-attribute AHP-FLP approach", International Journal of Soft Computing and Engineering, 2(6), pp. 11-17 (2013).

44. Kabak, M., Burmaoğlu, S., and Kazançoğlu, Y. "A fuzzy hybrid MCDM approach for professional selection", Expert Systems with Applications, 39(3), pp. 3516-3525 (2012).

45. Safarzadegan Gilan, S., Sebt, M.H., and Shahhosseini, V. "Computing with words for hierarchical competency based selection of personnel in construction companies", Applied Soft Computing, 12(2), pp. 860871 (2012).

46. Kelemenis, A., Ergazakis, K., and Askounis, D. "Support managers' selection using an extension of fuzzy TOPSIS", Expert Systems with Applications, 38(3), pp. 2774-2782 (2011).
47. Gabus, A. and Fontela, E., World Problems an Invitation to Further Thought within the Framework of DEMATEL, Battelle Geneva Research Centre, Switzerland (1972).

48. Akyuz, E. and Celik, E. "A fuzzy DEMATEL method to evaluate critical operational hazards during gas freeing process in crude oil tankers", Journal of Loss Prevention in the Process Industries, 38, pp. 243-253 (2015).

49. Yazdani, M., Chatterjee, P., Zavadskas, E.K., et al. "Integrated QFD-MCDM framework for green supplier selection", Journal of Cleaner Production, 142(4), pp. 3728-3740 (2017).

50. Pamučar, D., Mihajlović, M., and Obradović, R., et al. "Novel approach to group multi-criteria decision making based on interval rough numbers: Hybrid DEMATEL-ANP-MAIRCA model", Expert Systems with Applications, 88, pp. 58-80 (2017).

51. Cheng, C., Chen, C., Hsu, F., et al. "Enhancing service quality improvement strategies of fine-dining restaurants: New insights from integrating a twophase decision-making model of IPGA and DEMATEL analysis", International Journal of Hospitality Management, 31, pp. 1155-1166 (2012).

52. Tabrizi, B.H., Torabi, S.A., and Ghaderi, S.F. "A novel project portfolio selection framework: An application of fuzzy DEMATEL and multi-choice goal programming", Scientia Iranica, Transactions E: Industrial Engineering, 23(6), pp. 2945-2958 (2016).

53. Sahebjamnia, N. "Resilience supplier selection and order allocation under uncertainty", Scientia Iranica, Transactions E: Industrial Engineering, 27(1), pp. 411-426 (2020).

54. Akao, Y., Development History of Quality Function Deployment - The Customer Driven Approach to Quality Planning and Deployment, Tokyo, Japan: Asian Productivity Organization (1994).

55. Bottani, E. and Rizzi, A. "Strategic management of logistics service: A fuzzy QFD approach", International Journal of Production Economics, 103, pp. 585-599 (2006).

56. Bevilacqua, M., Ciarapicab, F.E., and Giacchetta, G. "A fuzzy-QFD approach to supplier selection", Journal of Purchasing \& Supply Management, 12(2006), pp. 14-27 (2006).

57. Liu, S., Jeffrey, F., and Yingjie, Y. "A brief introduction to grey systems theory", Grey Systems: Theory and Application, 2(2), pp. 89-104 (2012).

58. Kuo, M.S. and Liang, G.S. "Combining VIKOR with GRA techniques to evaluate service quality of airports under fuzzy environment", Expert Systems with Applications, 38, pp. 1304-1312 (2011).

59. Banaeian, N., Mobli, H., Fahimnia, B., Nielsen, I.E., et al. "Green supplier selection using fuzzy group decision making methods: A case study from the agri-food industry", Computers and Operations Research, 89, pp. 337-347 (2018). 
60. Pandey, R.K. and Panda, S.S. "Optimization of bone drilling parameters using grey-based fuzzy algorithm", Measurement, 47, pp. 386-392 (2014).

61. Peng, K. and Shen, Y. "A variable iterated greedy algorithm based on grey relational analysis for crew scheduling", Scientia Iranica, Transactions E: Industrial Engineering, 25(2), pp. 831-840 (2018).

62. Li, R.J. "Fuzzy method in group decision making", Computers and Mathematics with Applications, 38(1), pp. 91-101 (1999).

63. Opricovic, S. and Tzeng, G.H. "Defuzzification within a multicriteria decision model", International Journal of Uncertainty Fuzziness and Knowledge-Based Systems, 11(5), pp. 635-652 (2003).

64. Yager, R.R. "A procedure for ordering fuzzy subsets of the unit interval", Information Science, 24, pp. 143161 (1981).

65. Kulak, O. and Kahraman, C. "Fuzzy multi-attribute selection among transportation companies using axiomatic design and analytic hierarchy process", Information Sciences, 170, pp. 191-210 (2005).

66. Tang, X.Y., Wei, G.W., and Gao, H. "Models for multiple attribute decision making with interval-valued Pythagorean fuzzy muirhead mean operators and their application to green suppliers selection", Informatica, 30(1), pp. 153-186 (2019).

67. Tang, X.Y. and Wei, G.W. "Multiple attribute decision-making with dual hesitant Pythagorean fuzzy information", Cognitive Computation, 11(2), pp. 193211 (2019).

68. Tang, M., Wang, J., Lu, J.P., Wei, G.W., Wei, C., and Wei, Y. "Dual hesitant Pythagorean fuzzy Heronian mean operators in multiple attribute decision making", Mathematics, 7(344), pp. 1-27 (2019).

69. Wang, R., Wang, J., Gao, H., and Wei, G. "Methods for MADM with picture fuzzy muirhead mean operators and their application for evaluating the financial investment risk", Symmetry, 11(6), pp. 1-21 (2019).

70. Wei, G.W. and Zhang, Z.P. "Some single-valued neutrosophic Bonferroni power aggregation operators in multiple attribute decision making", Journal of Ambient Intelligence and Humanized Computing, 10(3), pp. 863-882 (2019).

\section{Appendix A: The main steps of fuzzy DEMATEL}

The main steps of the fuzzy DEMATEL method are described as follows:

Step 1: Generating the direct relation matrix. The first step consists of writing the pairwise comparison values of the criteria throughout columns and rows based on a predetermined linguistic scale according to decision-maker assessments using Eq. (A.1). In this step, a group of experts is asked to obtain direct relation matrices $\tilde{A}$, by linguistic terms to measure the relationship between criteria.

$$
\tilde{A}=\left[\begin{array}{cccc}
0 & (l, m, u)_{12} & \cdots & (l, m, u)_{1 n} \\
(l, m, u)_{21} & 0 & \cdots & (l, m, u)_{2 n} \\
\vdots & \vdots & \ddots & \vdots \\
(l, m, u)_{n 1} & (l, m, u)_{n 2} & \cdots & 0
\end{array}\right]
$$

Step 2: Normalizing the direct relation matrix. The criteria through which the evaluation or selection take place contain various scales and unit of measure. Therefore, in this step, these different data should be transformed into equally spaced data. The equation to transform the data is given in Eq. (A.2). All elements in the normalized direct relation matrix are between $0-1$, and all diagonal elements are equal to zero.

$$
\begin{aligned}
& \tilde{x}_{i j}=\frac{X}{r}=\left(\begin{array}{lll}
\frac{l_{i j}}{r_{1}} & \frac{m_{i j}}{r_{2}} & \left.\frac{u_{i j}}{r_{3}}\right) \quad 1 \leq j \leq n, \\
r_{1}=\max \left(\sum_{j=1}^{n} l_{i j}\right), & r_{2}=\max \left(\sum_{j=1}^{n} m_{i j}\right), \\
r_{3}=\max \left(\sum_{j=1}^{n} u_{i j}\right) .
\end{array}\right.
\end{aligned}
$$

Step 3: Attaining the total relation matrix. Once the normalized direct relation matrix is obtained, the total relation matrix is constituted using Eq. (A.3). To deal with this step total relation matrix can be divided into sub-matrices. These sub-matrices indicate the lower, middle, and upper numbers of the fuzzy set to simplify the calculation.

$$
\begin{aligned}
& \tilde{T}=\tilde{X}+\tilde{X}^{2}+\cdots=\sum_{i=1}^{\infty} \tilde{X}^{i}=\tilde{X}(I-\tilde{X})^{-1} \\
& X_{l}=\left[\begin{array}{cccc}
0 & l_{12} & \cdots & l_{1 n} \\
l_{21} & 0 & \cdots & l_{2 n} \\
\vdots & \vdots & \ddots & \vdots \\
l_{n 1} & l_{n 2} & \cdots & 0
\end{array}\right] \\
& X_{m}=\left[\begin{array}{cccc}
0 & m_{12} & \cdots & m_{1 n} \\
m_{21} & 0 & \cdots & m_{2 n} \\
\vdots & \vdots & \ddots & \vdots \\
m_{n 1} & m_{n 2} & \cdots & 0
\end{array}\right] \\
& X_{u}=\left[\begin{array}{cccc}
0 & u_{12} & \cdots & u_{1 n} \\
u_{21} & 0 & \cdots & u_{2 n} \\
\vdots & \vdots & \ddots & \vdots \\
u_{n 1} & u_{n 2} & \cdots & 0
\end{array}\right]
\end{aligned}
$$


Step 4: Defuzzification. This step is used to obtain the criteria crisp value after multiple calculations. The adopted defuzzification process CFCS, which was introduced by Opricovic and Tzeng [63], includes four stages, namely normalization, right, and left hand side normalized values, total normalized value, and crisp values. The crisp values are calculated according to Eqs. (A.4)-(A7).

Normalization:

$$
\begin{aligned}
& x l_{i j}=\left(l_{i j}-\min l_{i j}\right) / \Delta_{\min }^{\max }, \\
& x m_{i j}=\left(m_{i j}-\min m_{i j}\right) / \Delta_{\min }^{\max }, \\
& x u_{i j}=\left(u_{i j}-\min u_{i j}\right) / \Delta_{\min }^{\max }, \\
& \Delta_{\min }^{\max }=\max u_{i j}-\min l_{i j} .
\end{aligned}
$$

Right and left hand side normalized values:

$$
\begin{aligned}
& x l s_{i j}=x m_{i j} /\left(1+x m_{i j}-x l_{i j}\right), \\
& x r s_{i j}=x u_{i j} /\left(1+x u_{i j}-x m_{i j}\right) .
\end{aligned}
$$

Total normalized values:

$$
\begin{aligned}
x_{i j}= & {\left[x l s_{i j}\left(1-x l s_{i j}\right)+x r s_{i j} \times x r s_{i j}\right] } \\
& /\left[1-x l s_{i j}+x r s_{i j}\right] .
\end{aligned}
$$

Crisp values:

$$
z_{i j}=\min l_{i j}+x_{i j} \Delta_{\min }^{\max } .
$$

Step 5: Obtaining $\left(D_{i}+R_{i}\right)\left(D_{i}-R_{i}\right)$ values through calculating the weights. The sum of rows and columns elements $z_{i j}$ give $D_{i}$ and $R_{i}$ values of the related criterion, respectively. By using Eq. (A.8), the weights of the criteria $w_{i}$ are obtained. $\left(D_{i}-R_{i}\right)$ indicates the net effect that criterion has on the system. In particular, if the value of $\left(D_{i}-R_{i}\right)$ is positive, the factor will be a net cause. When $\left(D_{i}-R_{i}\right)$ is negative, the factor will be a net result clustered into effect group [48].

$$
\begin{aligned}
& w_{i}=\sqrt{\left(D_{i}+R_{i}\right)^{2}+\left(D_{i}-R_{i}\right)^{2}}, \\
& W_{i}=\frac{w_{i}}{\sum_{i=1}^{n} w_{i}}, \quad i=1,2, \cdots, n .
\end{aligned}
$$

\section{Appendix B: The main steps of fuzzy QFD}

The basic steps of the QFD method are as follows:
Step 1: Generate relations and correlation matrices. According to the assessment expressed by the decision maker, the paired comparison values based on the social and technical criteria of the predetermined language scale constitute the relationship matrix. Similarly, the correlation matrix is obtained by calculating the correlation between the technical requirements;

Step 2: Obtaining relative importance values of technical requirements. This step includes calculating the weight of the technical standards using the social standards and their weights according to the relationship matrix, without considering the correlation values between the technical criteria;

Step 3: Calculating the weights of technical requirements. However, in the previous step, the calculations include importance values of technical requirements by using social attributes, however, in this step the inner dependencies between the TR are not considered. Once relative importance values of technical criteria are obtained, the weights of technical criteria are calculated by adding correlation matrix values and the relative importance value of the criteria;

Step 4: Defuzzification of the weights of technical requirements. To attain crisp values of the weights of technical criteria, the method introduced by Yager [64] shown in Eq. (B.1) is utilized:

$$
w T R_{j}=\frac{l+2 m+u}{4} .
$$

\section{Appendix C: The main steps of fuzzy GRA}

The basic steps of the fuzzy GRA method are explained below:

Step 1: Constituting the decision matrix. The method starts with constituting the decision matrix, which includes the evaluation of the alternatives based on the selected criteria according to a predetermined linguistic scale. The decision matrix represents the assessment scores of $m$ alternatives based on $n$ criteria specified by the decision-makers and is shown in Eq. (C.1).

$$
\tilde{X}=\left[\begin{array}{cccc}
(l, m, u)_{11} & (l, m, u)_{12} & \cdots & (l, m, u)_{1 n} \\
(l, m, u)_{21} & (l, m, u)_{22} & \cdots & (l, m, u)_{2 n} \\
\vdots & \vdots & \ddots & \vdots \\
(l, m, u)_{m 1} & (l, m, u)_{m 2} & \cdots & (l, m, u)_{m n}
\end{array}\right] \dot{(C .1)}
$$

Step 2: Normalizing the decision matrix. The process of normalization is different from the purpose of the problem. For maximization objective Eq. (C.2) is used, whereas for minimization objective Eq. (C.3) is adopted. The normalized decision matrix 
$\tilde{R}$ consists of the elements $\tilde{r}_{i j}$ that are obtained using Eqs. (C.2) and (C.3).

$$
\begin{aligned}
\tilde{r}_{i j} & =\left(\begin{array}{lll}
\frac{l_{i j}}{u_{j}^{+}} & \frac{m_{i j}}{u_{j}^{+}} & \frac{u_{i j}}{u_{j}^{+}}
\end{array}\right), \\
i & =1,2, \cdots, m \quad j=1,2, \cdots, n, \\
u_{j}^{+} & =\max \left\{u_{i j}\right\} \\
\tilde{r}_{i j} & =\left(\begin{array}{ll}
\frac{l_{j}^{-}}{u_{i j}}, \quad \frac{l_{j}^{-}}{m_{i j}}, & \frac{l_{j}^{-}}{l_{i j}}
\end{array}\right), \\
i & =1,2, \cdots, m, \quad j=1,2, \cdots, n \\
l_{j}^{-} & =\min \left\{l_{i j}\right\} .
\end{aligned}
$$

Step 3: Determining the reference series. The desired values according to objective function type and using Eqs. (C.4) and (C.5) for maximization and minimization, are determined. Reference series $\tilde{R}_{0}$ contain maximum or minimum assessment values based on $n$ criteria:

$$
\begin{aligned}
\tilde{R}_{0} & =\left[\tilde{r}_{01}, \tilde{r}_{02}, \cdots, \tilde{r}_{0 n}=\max \left(\tilde{r}_{i j}\right)\right], \\
j & =1,2, \cdots, n, \\
\tilde{R}_{0} & =\left[\tilde{r}_{01}, \tilde{r}_{02}, \cdots, \tilde{r}_{0 n}=\min \left(\tilde{r}_{i j}\right)\right], \\
& j=1,2, \cdots, n .
\end{aligned}
$$

Step 4: Constructing the distance matrix. The distance matrix $\Delta_{0 m}$ shows the variation of the alternative values from the reference series and is depicted in Eq. (C.6). Each element of the distance matrix $\Delta_{0 m}(n)$ is calculated using Eq. (C.7) where $\tilde{A}$ and $\tilde{B}$ show $\tilde{r}_{i j}$ and $\tilde{R}_{0}$.

$\Delta_{0 m}=\left[\begin{array}{ccc}\Delta_{01}(1) & \Delta_{01}(2) & \Delta_{01}(n) \\ \Delta_{02}(1) & \Delta_{02}(2) & \Delta_{02}(n) \\ & & \\ \Delta_{0 m}(1) & \Delta_{0 m}(2) & \Delta_{0 m}(n)\end{array}\right]$,

$d(\tilde{A}, \tilde{B})=\sqrt{\frac{1}{3}\left[\left(l_{1}-l_{2}\right)^{2}+\left(m_{1}-m_{2}\right)^{2}+\left(u_{1}-u_{2}\right)^{2}\right]}$.

Step 5: Constituting the grey relational coefficient matrix. The constituting elements $\gamma_{0 m}(n)$ of grey relational coefficient matrix $\gamma_{0 m}$, which can be seen in Eq. (C.8), is calculated by Eq. (C.9) where $\xi$ is resolving coefficient and in the range of $[0,1]$ :

$$
\begin{aligned}
& \gamma_{0 m}=\left[\begin{array}{cccc}
\gamma_{01}(1) & \gamma_{01}(2) & \cdots & \gamma_{01}(n) \\
\gamma_{02}(1) & \gamma_{02}(2) & \cdots & \gamma_{02}(n) \\
\vdots & \vdots & \ddots & \vdots \\
\gamma_{0 m}(1) & \gamma_{0 m}(2) & \cdots & \gamma_{0 m}(n)
\end{array}\right] \\
& \gamma_{0 m}(n)=\frac{\Delta_{\min }+\xi \Delta_{\max }}{\Delta_{0 i}(j)+\xi \Delta_{\max }}
\end{aligned}
$$

Step 6: Calculating the grey relational grades The importance values $\Gamma_{0 i}$ of each alternative are calculated using Eq. (C.10):

$$
\begin{aligned}
\Gamma_{0 i} & =\sum_{j=1}^{n}\left[w T R_{j} \gamma_{0 i}(j)\right], \\
i & =1,2, \cdots, m, \quad j=1,2, \cdots, n .
\end{aligned}
$$

\section{Biographies}

Elif Özgörmüş is currently working as an Assistant Professor in Industrial Engineering Department of Pamukkale University, Turkey. She took her PhD and MSc from Auburn University, USA in 2015 and 2011, respectively. Her major research areas are facility layout optimization, retail management and human resource management.

Ahmet Alp Şenocak is a Research Assistant in the field of Operational Research at the Department of Industrial Engineering, Pamukkale University, Turkey. He received his BS degree in Industrial Engineering from Dokuz Eylul University, Turkey. He is currently a PhD student in Industrial Engineering at Pamukkale University, Turkey, where he received his MSc from. His research interests focus on multi criteria decisionmaking, production planning, bioenergy supply chain modelling.

Hacer Güner Gören is an Associate Professor at the Department of Industrial Engineering at Pamukkale University, Turkey. She received her BS degree in Industrial Engineering from Dokuz Eylul University, Turkey in 2002, her MS degree in Industrial Engineering from Pamukkale University, Turkey in 2005 and her PhD degree in Industrial Engineering from Dokuz Eylul University, Turkey in 2011. Her main research interests are modelling and optimisation algorithms for production planning problems and multi criteria decision-making. 